\title{
Üniversite öğrencilerinde astenopik şikayetlerin ve internet bağımlıı̆̆ının ilişkisinin değerlendirilmesi
}

\author{
Evaluation of the relationship between asthenopic complaints and internet addiction in \\ university students \\ Hüseyin Kaya
}

Gönderilme tarihi:21.05.2019

Kabul tarihi:23.08.2019

\section{Özet}

Amaç: Çalışmanın amacı üniversite öğrencilerinde astenopik şikayetlerle internet bağımlılı̆̆ arasında bir ilişki olup olmadığını göstermektir.

Gereç ve yöntem: Pamukkale Üniversitesi'nin çeşitli fakültelerinde öğrenim gören 540 öğrenci çalışmaya dahil edildi. Bu öğrencilere genel bilgiler, astenopi şikayetleri ve internet bağımlılığı ile ilgili sorular içeren anket uygulandı. Veriler Spss 21. ile analiz edildi.

Bulgular: Çalışmaya katılanların $34{ }^{\prime} \mathrm{i}(\% 63,9)$ kadın $195{ }^{\prime} \mathrm{i}(\% 36,1)$ erkektir. Katılımcıların yaş ortalaması $19,85 \pm 1,78$ olarak bulunmuştur. Astenopi skorlarıyla internet kullanım süresinin, internet bağımlılık skorlarının arasında pozitif yönde bir ilişki olduğu bulunmuştur $(p=0,0001)$.

Sonuç: Internet bağımlıı̆̆ı skorları ile astenopik şikayetler arasında anlamlı bir ilişki bulunmuştur. Bu nedenle gençler internet kullanımı sırasında göz sağlıklarını korumaları için bilinçlendirilmelidir.

Anahtar Kelimeler: Astenopi, internet bağımlıı̆̆ı, göz yorgunluğu, üniversite öğrencileri.

Kaya H. Üniversite öğrencilerinde astenopik şikayetlerin ve internet bağımlıı̆ının ilişkisinin değerlendirilmesi. Pam Tıp Derg 2019;12:561-567.

\begin{abstract}
Purpose: The aim of the study was to show whether there is a relationship between asthenopic complaints and internet addiction in university students.

Materials and methods: 540 students from various faculties of Pamukkale University were included in the study. A questionnaire containing general information, asthenopia complaints and internet addiction was applied to these students. Data were analyzed with Spss 21.

Results: 345 (63.9\%) of the participants were female and 195 (36.1\%) were male. The mean age of participants was $19.85 \pm 1.78$. Asthenopia scores was found to have a positive correlation with internet usage time and internet addiction scores $(p=0.0001)$.

Conclusion: There was a significant relationship between internet addiction scores and asthenopic complaints. For this reason, young people should be made aware of the need to protect eye health during internet use.
\end{abstract}

Key Words: Asthenopia, internet addiction, eye fatigue, college students.

Kaya $\mathrm{H}$. Evaluation of the relationship between asthenopic complaints and internet addiction in university students. Pam Med J 2019;12:561-567.

\section{Giriş}

İnternet kullanımı gençlerin yaşamının önemli bir parçası haline gelmektedir. Hatta genç nüfus için her alanda kullanılan bir araçtır. Akademik olarak internetin kullanım amacı çoğunlukla öğrenmeye ve araştırmaya yönelik olmaktadır. İnternetin bilgi edinme gibi faydalarının yanında, herkesin kullanımına açık olmasından kaynaklanan internet ortamında bilgi ayırımı, aşırı bilgi yüklemesi ve güvensiz bilgiye olanak vermesi gibi problemler de söz konusu olabilmektedir [1]. Ayrıca internetin kumar, sohbet, oyun gibi kullanım amaçlarının internet bağımlıı̆ıının oluşmasında önemli rol oynayabileceği düşünülmektedir [2-4].

Çeşitli çalışmalarda internet bağımlılığının genç nüfusdaki sıklığı araştırımıştır. Kore'de yapılan bir çalışmada adolesanlarda internet bağımlılığının \%4,3 olduğu belirtilmiştir [4]. Ülkemizde yapılan bir diğer çalışmada bu oran \%11,6 olarak bulunmuştur [5]. İnternet bağımlıı̆̆ı ve psikiyatrik hastalıkların incelendiği

Hüseyin Kaya, Dr. Öğretim Üyesi, Pamukkale Üniversitesi Tıp Fakültesi Göz Hastalıkları Anabilim Dalı, DENiZLI, e-posta:hsynkaya@gmail.com (orcid.org/0000-0001-9633-3173) (Sorumlu yazar) 
bir derlemede internet bağımlılığının hem batı hem de doğu toplumlarını etkileyen bir sorun olduğu ve bu sorunun global bir sorun olarak önemle üzerinde durulması gerektiği belirtilmiştir. Erken yaşta internete maruziyetin ve çevresel faktörlerin internet bağımlılığında önemli rol oynadığı düşünülmektedir [6].

Astenopi göz yorgunluğu manasına gelmektedir. Başağrısı, göz ağrısı, göz yaşarması, sulanma, kuruluk, bulanık görme, çift görme, yabancı cisim hissi gibi semptomlarla kendini gösterir [7]. Modern dünyada elektronik aletlerin kullanımının artmasıyla beraber görsel performans gerektiren işlerin süresinin artmasına bağlı olarak astenopinin sıklığı artmaktadır [8].

$\mathrm{Biz}$ de çalışmamızda üniversite öğrencilerinde astenopi bulgularını ve internet bağımlılığını yönelttiğimiz anket sorularıyla araştırmayı amaçladık. Araştırdığımız kadarıyla ülkemizde astenopi ile internet bağımlılığının ilişkilendirildiği bir çalışma bulunmamaktadır. Çalışmamızdan çıkan sonuçların ülkemizde astenopi ile internet bağımlılığı arasındaki ilişkiye ışık tutacağını düşünmekteyiz.

\section{Gereç ve yöntem}

$\mathrm{Bu}$ çalışma için Pamukkale Üniversitesi Girişimsel Olmayan Klinik Araştırmalar Etik Kurulu'ndan gerekli izin 25.12.2018 tarih ve 24 sayılı toplantıyla alınmıştır. Bu çalışma 15 Ocak-15 Mart 2019 tarihleri arasında Pamukkale Üniversitesi Eğitim Fakültesi'nde, Fen-Edebiyat Fakültesi'nde, İktisadi ve İdari Bilimler Fakültesi'nde, Mühendislik Fakültesi'nde, Teknoloji Fakültesi'nde, Kale
Meslek Yüksekokulu'nda, Tavas Meslek Yüksekokulu'nda ve Tıp Fakültesi'nde öğretim görmekte olan 540 üniversite öğrencisi üzerinde yapılan kesitsel tipte bir araştırmadır.

Çalışmamızda yapılacak olan anket genel bilgi, astenopi anketi ve internet bağımlılığı anketi olarak üç ayrı bölümden oluşmaktadır. Genel bilgi kısmında cinsiyet, yaş gibi kişilerin sosyodemografik özellikleri, sigara içip içmedikleri, göz hastalıkları olup olmadığı, interneti günde kaç saat kullandıkları, internet kullanırken daha iyi görmek için alet kullanıp kulanmadıkları, internete erişim yöntemleri, düzenli kitap okuma alışkanlıkları olup olmadığı, interneti hangi amaçla kullandıkları, televizyon izleme alışkanlıkları olup olmadığı bilgileri sorgulanacaktır.

Astenopi anketinde ise gözlerde yorgunluk hissi, ağrı-acıma hissi, gözlerde tahriş hissi, gözlerde sulanma, kuruluk hissi, gerginlik hissi, yanma hissi, görmede bulanıklık, odaklanmada zorluk, gözlerde rahatsızlık-huzursuzluk hissi gibi göz yorgunluğunu değerlendirmeye yönelik daha önce başka yayınlarda kullanılmış sorular sorulacaktır [9, 10]. Tablo 1'de astenopi değerlendirme formu görülmektedir. Bu form Kim Ju. ve ark.'ın çalışmasından Türkçeye çevrilerek katılımcılara uygulanmıştır [9].

Üçüncü bölümde ise standart bir internet bağımlılığı anketi yapılacak yoksunluk, kontrol güçlüğü, işlevsellikte bozulma, sosyal izolasyon gibi alt başlıklarla kişilerin bağımlııkları değerlendirilecektir. İnternet bağımlılığı anketi Türkiye için özel olarak geliştirilen bir ankettir [11]. Tablo 2'de internet bağımlılık ölçeği görülmektedir.

Tablo 1. Astenopi değerlendirme formu.

\begin{tabular}{lllll}
\hline Semptom & Yok & Hafif & Orta & Ağır \\
Yorgunluk hissi & 0 & 1,2 & 3,4 & 5,6 \\
Ağrı-acıma hissi & 0 & 1,2 & 3,4 & 5,6 \\
Tahriş hissi & 0 & 1,2 & 3,4 & 5,6 \\
Sulanma & 0 & 1,2 & 3,4 & 5,6 \\
Kuruluk hissi & 0 & 1,2 & 3,4 & 5,6 \\
Gerginlik hissi & 0 & 1,2 & 3,4 & 5,6 \\
Yanma hissi & 0 & 1,2 & 3,4 & 5,6 \\
Görmede bulanıklık & 0 & 1,2 & 3,4 & 5,6 \\
Odaklanmada zorluk & 0 & 1,2 & 3,4 & 5,6 \\
Rahatsızlık-huzursuzluk hissi & 0 & 1,2 & 3,4 & 5,6 \\
\hline
\end{tabular}


Tablo 2. İnternet bağımlılık ölçeği.

\section{INTERNET BAĞIMLILIK ÖLÇEĞi}

Aşağıdaki her bir maddeyi okuyarak, bu madde sizin için her zaman doğru ise "Tamamen Katılıyorum", genelde doğru ise "Katılıyorum”, emin değilseniz "Kararsızım”, genelde doğru değilse "Katılmıyorum", hiçbir zaman doğru değilse "Kesinlikle Katılmıyorum" şeklinde işaretleme yapmanız rica olunur.

\section{Yoksunluk}

1. İnternet kullanamadığım zaman kendimi gergin/huzursuz .

2. İnternet kullanmak isteyip de kullanamadığım zaman sinirli/öfkeli olurum.

3. İnternet bağlantısı koparsa ya da yavaşlarsa sinirlenirim/öfkelenirim.

4. İnternet kullandığım zamanlarda hiç olmadığım kadar mutlu/huzurlu olurum.

5. Kendimi endişeli ya da sıkıntılı hissettiğim zamanlarda internet kullanmak beni rahatlatır.

6. Birileri beni internetin başından kaldırırsa sinirlenirim.

7. Sorunlarımdan kaçmak için internet kullanmaya yönelirim.

8. İnternete, planladığım zamanda giremezsem sinirlenirim.

9. Çevremde birileri varken, yalnız kalıp, internete girmeyi isterim.

10. İnterneti kullanmadığım zamanlarda internete girmek için sabırsızlanırım.

11. Gittiğim yerlerde internet bağlantısı ararım.

\section{Kontrol güçlüğü}

12. İnternet kullanmamı sınırlamakta ya da kontrol etmekte güçlük çekerim.

13. Sabah uyandığımda ilk aklıma gelen internete girmek olur.

14. İnternette her defasında, bir öncekinden daha uzun süre kalmak isterim.

15. İnternette planladığımdan daha uzun süre kalırım.

16. İnternet kullanmadığım zamanlarda bile interneti düşünürüm.

17. İnternette iken acıktığımı, susadığımı hissetmem ya da farkına varmam.

18. İnternette daha fazla zaman geçirmek için başka planlarımı iptal ederim.

19. İstediğim zaman internetin başından kalkamam.

20. Ailem beni çağırsa dahi internetin başından kalkamam.

21. İnternet kullanabilmek için uykumdan ödün veririm. İşlevsellikte bozulma

22. İnternet kullanmamdan dolayı ailem ile sorunlar yaşarım.

23. Arkadaşlarım beni çağırsa dahi internetin başından kalkamam.

24. İnternet kullanmamdan dolayı başka etkinliklere (spor, sinema, kitap okuma vb.) ilgim azalır.

25. İnternet kullanmamdan dolayı ev/iş/okul sorumluluklarımı yerine getiremem ya da inmal ederim.

26. Çevremdekiler internette harcadığım zamandan dolayı şikayet eder.

27. İnternet kullanmamdan dolayı ailem ile daha az zaman geçiririm.

28. İnternet kullanmamdan dolayı arkadaşlarım ile daha az zaman geçiririm.

Sosyal izolasyon

29. İnternet kullanmamdan dolayı arkadaşlarım ile sorunlar yaşarım.

30. İnternet ortamında edindiğim arkadaşlıkları gerçek yaşamdaki arkadaşlarıma tercih ederim.

31. Gerçek yaşamdaki arkadaşlarımla dışarıda görüşmek yerine internette görüşmeyi tercih ederim.

32. Arkadaşlarımı internetten edinirim.

33. İnternet benim en iyi arkadaşımdır.

34. İnternetsiz bir yaşam bana anlamsız/boş gelir.

35. İnternet kullanmamdan dolayı yüz yüze iletişimde zorluk yaşarım. 
Elde edilen veriler IBM SPSS (versiyon 21,0) istatistik paket programında değerlendirildi. Verilerin analizinde Ki-kare testi, Spearman Korelasyon Analizi ve Lojistik Regresyon Analizi kullanıldı. İstatistiksel anlamlılık değeri $p<0,05$ olarak kabul edildi.

\section{Bulgular}

Çalışmaya katılanların 345 'i $\quad(\% 63,9)$ kadın 195'i $(\% 36,1)$ erkektir. Katılımcıların yaş ortalaması 19,85 $\pm 1,78$ (17-30) olarak bulunmuştur. Katılımcıların 425'i günde 1 veya hiç sigara içmediğini belirtirken, 56'sı 2 ile 5 arası, 57'si günde 1 paket, 2'si ise günde 1 paketten fazla sigara içtiğini belirtmiştir.
Sigara kullanım miktarıyla astenopi ve internet bağımlılık ölçeği skorları arasında anlamlı bir ilişki saptanmamıştır $(p>0,05)$. Katılımcıların 432'si (\%80) internet kullanırken gözlük ya da lens kullanmadığını, 108'i (\%20) ise gözlük ya da lens kullandığını belirtmiştir.

Tablo 3'te interneti kullanım amaçları ve internete ulaşım kaynakları belirtilmiştir.

Tablo 4'te günlük internet kullanım süresi, gözlük ya da lens kullanımının olup olmadığı, internete erişim yolu, kitap ya da gazete okuma alışkanlığı ve televizyon izleme alışkanlığı olup olmadığı sorularına verilen cevaplar belirtilmiştir.

Tablo 3. Katılımcıların internet kullanım amaçları ve ulaşım araçları.

\begin{tabular}{lll}
\hline İnternet kullanım amacı & Cevap sayısı & Yüzde \% \\
Ödev yapmak & 227 & 16,9 \\
Oyun oynamak & 70 & 5,2 \\
Sosyal medya kullanımı & 449 & 33,5 \\
Video ya da müzik & 283 & 21,1 \\
Araştırma yapmak & 232 & 17,3 \\
Gazete ve/veya haber okumak & 76 & 5,6 \\
İnternete ulaşım aracı & & \\
Bilgisayar & 3 & 0,6 \\
Cep telefonu & 337 & 62,4 \\
Her iki araçla & 200 & 37 \\
\hline
\end{tabular}

Tablo 4. Katılımcıların internet kullanım süreleri, alışkanlıkları ve gözlük ya da lens kullanım özellikleri.

\begin{tabular}{lcc}
\hline Günlük İnternet kullanım süresi & Cevap sayısı & Yüzde (\%) \\
0-1 saat & 22 & 4,1 \\
1-2 saat & 66 & 12,2 \\
2-3 saat & 124 & 23,0 \\
3-4 saat & 137 & 25,4 \\
4 saatten fazla & 191 & 35,4 \\
Toplam & 540 & 100 \\
Gözlük ya da lens kullanımı & & \\
Var & 108 & 20 \\
Yok & 432 & 80 \\
Kitap ya da gazete okuma alışkanlığı & & \\
Var & 237 & 43,9 \\
Yok & 303 & 56,1 \\
Televizyon izleme alışkanlığı & & 32,2 \\
Var & 174 & 67,8 \\
Yok & 366 &
\end{tabular}


Tablo 5'te astenopi ile ilişkiliolan değişkenlerin regresyon modeli ve parametreleri belirtilmiştir. İnternet bağımlılığı toplam skoru, yoksunluk, kontrol güçlüğü, işlevsellikte bozulma, sosyal izolasyon, internet kullanım süresi için $p=0,0001$ olarak bulunmuştur.
Tablo 6'da astenopi ve internet bağımlılığı skorları verilmiştir. İnternet bağımlılığı toplam skoru yanında yoksunluk, kontrol güçlüğü, işlevsellikte bozulma, sosyal izolasyon alt başlıklarından alınan skorlar da verilmiştir. Cronbach alfa değerleri astenopi ve internet bağımlılığı için 0,94 olarak bulunmuştur.

Tablo 5. Astenopi ile ilişkili olduğu saptanan değişkenlerin regresyon modeli tablosu.

\begin{tabular}{|c|c|c|c|c|c|c|c|}
\hline & \multicolumn{2}{|c|}{$\begin{array}{l}\text { Standart olmayan } \\
\text { Katsayilar }\end{array}$} & \multirow{2}{*}{$\begin{array}{l}\text { Standart } \\
\text { katsayılar } \\
\text { Beta }\end{array}$} & \multirow[t]{2}{*}{$\mathrm{T}$} & \multirow[t]{2}{*}{$P$} & \multicolumn{2}{|c|}{$\begin{array}{l}95.0 \% \text { Güven aralığı(B } \\
\text { için) }\end{array}$} \\
\hline & B & SE & & & & Alt sınır & Üst sınır \\
\hline $\begin{array}{l}\text { İnternet bağımlılığı } \\
\text { toplam skor }\end{array}$ & 0,171 & 0,027 & 0,265 & 6,368 & $0,0001^{*}$ & 0,118 & 0,224 \\
\hline Yoksunluk & 0,344 & 0,066 & 0,221 & 5,247 & $0,0001^{*}$ & 0,215 & 0,473 \\
\hline Kontrol güçlüğü & 0,487 & 0,083 & 0,246 & 5,890 & $0,0001^{*}$ & 0,325 & 0,649 \\
\hline İşlevsellikte bozulma & 0,607 & 0,114 & 0,224 & 5,343 & $0,0001^{*}$ & 0,384 & 0,831 \\
\hline Sosyal izolasyon & 0,633 & 0,137 & 0,196 & 4,632 & $0,001^{*}$ & 0,365 & 0,902 \\
\hline Yaş & $-0,042$ & 0,316 & $-0,006$ & $-0,132$ & 0,895 & $-0,662$ & 0,579 \\
\hline $\begin{array}{l}\text { İnternet kullanım } \\
\text { süresi }\end{array}$ & 1,557 & 0,475 & 0,140 & 3,275 & $0,001^{*}$ & 0,623 & 2,490 \\
\hline
\end{tabular}

SE: Standart hata, ${ }^{*} p<0,05$

Tablo 6. Astenopi ve internet bağımlılık ölçeği skorları. Ortalama, ortanca, Cronbach alfa değerleri.

\begin{tabular}{llll}
\hline & A.O \pm S.D. & Ortanca (min - maks) & Cronbach alfa \\
\hline $\begin{array}{l}\text { Astenopi skoru } \\
\text { İnternet bagımlılığı } \\
\text { skoru }\end{array}$ & $14,05 \pm 3,09$ & $9,5(0-60)$ & 0,94 \\
Yoksunluk & $75,46 \pm 20,25$ & $74(35-158)$ & 0,94 \\
Kontrol güçlügü & $30 \pm 8,4$ & $30(11-55)$ & 0,87 \\
İslevsellikte bozulma & $21,47 \pm 6,62$ & $21(10-45)$ & 0,85 \\
Sosyal izolasyon & $12,6 \pm 4,84$ & $12(7-31)$ & 0,87 \\
\hline
\end{tabular}

A.O: Aritmetik ortalama S.D: Standart Sapma

\section{Tartışma}

Çalışmamızda genç popülasyonda internet bağımlılı̆ı ile astenopik şikayetler arasında anlamlı bir ilişki olduğu ve internet bağımlılık ölçeği skorlarının artmasıyla astenopi skorlarının anlamlı bir şekilde arttığı görülmüştür. Ayrıca yoksunluk, kontrol güçlügü, işlevsellikte bozulma, sosyal izolasyon alt başlıklarıyla da astenopik şikayetlerin ilişkili olduğu ve bunların astenopik şikayetleri anlamlı bir şekilde artırdığı görülmüştür.
Ülkemizde ve dünyada internet her geçen gün gençler arasında çeşitli amaçlarla daha da sık kullanılmaktadır. Bu nedenle de kötüye kullanım ve patolojik internet bağımlılığı giderek daha fazla gençleri tehdit etmektedir. Çalışmamızda internetin kullanım amaçlarına baktığımızda $\% 33,5$ oranla sosyal medya kullanımı en sık kullanım amacı olarak karşımıza çıkmıştır. Bunu $\% 21,1$ ve $\% 17,3$ ile video-müzik ve araştırma yapmak takip etmektedir. Daha önce yapılan bir çalışmada en sık internet kullanma nedeni sanal sohbet yapmak olarak bulunmuştur [12]. 
Ülkemizde yapılan bir diğer çalışmada ise ödev yapmak/ders çalışmak olarak bulunmuştur [13]. Çalışmalar arasındaki bu farklılıklar hem farklı zamanlarda yapıldığı için hem de farklı coğrafi ve kültürel bölgelerde yapıldığı için ortaya çıkmış olabilir.

Çalışmamızda astenopiyi değerlendirmek için uygulanan anket daha önce DJ Kim ve ark. tarafından 19 katılımcı üzerinde tablet kullanımına bağlı göz yorgunluğunu değerlendirmek için kullanılmıştır [9]. Bu çalışmada katılımcılara bir saat tablet kullanımı öncesinde ve sonrasında astenopik şikayetlere ve kuru göz bulgularına bakılmış ve anlamlı bir şekilde değiştiği görülmüştür. Ayrıca YW Suh ve ark.'ın yaptığı 60 katılımcının olduğu diğer bir çalışmada ortam ışığının göz yorgunluğuna etkisini değerlendirmede astenopi anketi kullanılmış ve ortam ışığının göz yorgunluğu semptomlarını artırdığı gösterilmiştir [10]. Her iki çalışmada katılımcı sayısı oldukça düşük sayılardadır. Bu çalışmalara göre bizim çalışmamızdaki kişi saysının fazla olması astenopi anketinden alınan sonuçların oldukça güvenilir olduğunu düşündürmektedir.

Son yıllarda internet erişiminde cep telefonu ve bilgisayar kullanımı artık hayatımızın ayrımaz bir parçası haline gelmiştir. Hatta cep telefonları hayatımızda neredeyse bir zorunluluk haline gelmiştir. Bu durum akıllı cihaz bağımlılığı gibi yeni problemleri beraberinde getirmiştir [14]. Günde bir saatten fazla tablet kullanımının gözyaşı kırılma zamanını etkilediği daha önce gösterilmiştir [9]. Ayrıca günde iki saat bilgisayar kullanımının gözyaşı fonksiyonunu bozduğu bildirilmiştir [15]. Bizim çalışmamızda bir saatten fazla internet kullanımı oranı \%95,9 iken iki saatten fazla internet kullananların oranı ise $\% 83,7$ olarak bulunmuştur. Günlük internet kullanımı süresi arttıkça astenopik şikayetlerin de anlamlı derecede arttığı görülmüştür. Bu durum gözyaşının miktarının azalmasına ya da kalitesinin bozulmasına bağlı olabilir. Nitekim, Sağlan $R$ ve ark.'ın çalışmalarında internet bağımlılığının kuru göz şikayetlerini artırdığını göstermiştir [13].

Çalışmamızda katılımcıların \%62,4'ü internete ulaşmak için cep telefonunu, \%37'si ise hem bilgisayar hem cep telefonunu kullandığını belirtmiştir. Bilgisayar ve cep telefonu kullanımının akomadasyonu azalttığı ve yakın nokta konverjansını etkilediği bilinmektedir [16, 17]. Ayrıca bilgisayar gibi dijital cihazların göz kırpma sayısını azalttığı bilinmektedir [18]. Tüm etkenlerin astenopik şikayetlerin artmasında etkili olduğunu düşünmekteyiz.

İnternet bağımlılık skorlarını elde etmek için kullandığımız ölçek ülkemiz için Günüç S. ve Kayri M. tarafından özel olarak geliştirilmiştir [11]. Bu çalışmada ölçeğin güvenilirliği için iç tutarlılık katsayısı olarak Cronbach alfa değeri kullanılmış ve bu değer tüm test için 0,94 olarak bulunmuştur. Bizim çalışmamızda da bu değer tüm ölçek için 0,94 bulunmuştur. Buradan uyguladığımız bu ölçeğin yüksek derecede tutarlı olduğunu söyleyebiliriz. Ayrıca yoksunluk, kontrol güçlüğü, işlevsellikte bozulma, sosyal izolasyon alt başlıklarında da Cronbach alfa değerleri hesaplanmış ve Günüç $S$. ve Kayri M.'nin çalışmasıyla benzer şekilde tutarlı oldukları görülmüştür [11].

Çalışmanın kısıtlıklarından bahsedecek olursak öncelikle çalışmamız Pamukkale Üniversitesinde okuyan öğrencilerle yapıldığı için bu bölge hakkında daha iyi fikir vermektedir. Ülkemiz genelinde çok merkezli çalışmalara intiyaç vardır. Ayrıca yaş grubumuz sadece üniversite öğrencileri ile sınırlıdır. Daha genç ve daha yaşlı populasyonların olduğu çalışmalara ihtiyaç vardır. Ayrıca astenopi anketinin yanında kuru göz belirteçleri ya da kuru göz değerlendirme anketleri daha başka çalışmalarda yapılabilir.

Internet bağımlıı̆ı̆ın sigara bağımlıı̆ı ile benzer mekanizmaya sahip olması nedeniyle her iki bağımlıı̆ı̆ın ilişkili olduğu düşünülmektedir [19]. Literatürde bazı çalışmalarda sigara kullanımıyla internet bağımlıı̆ı ilişkili bulunmuştur [13, 19]. Bazı çalışmalar da tam tersine bir ilişki olmadığını göstermiştir [20, 21]. Bizim çalışmamızda da internet bağımlıık ölçeği skoruyla sigara kullanım miktarının ilişkili olmadığı bulunmuştur.

Sonuç olarak, üniversite öğrencilerinde yaptığımız bu çalışmayla internet bağımlıı̆̆ ile astenopik şikayetler arasında kuvvetli bir ilişki olduğu ve internet bağımlılık ölçeği skorlarının artmasıyla astenopik şikayetlerin arttığını gösterdik. Ayrıca gençler arasında internet kullanım sürelerinin ne kadar fazla olduğunu gösterdik. Bu nedenle internet bağımlılığı bir toplum sağlığı sorunu olarak görülmeli ve gençler 
bilinçlendirilmeli ve göz sağlıklarını korumaya yönelik önlemler almaya yönlendirilmelidir.

Çıkar İlişkisi: Yazarlar çıkar ilişkisi olmadığını beyan eder.

\section{Kaynaklar}

1. Kim S, Kim R. A study of internet addiction: Status, causes, and remedies-focusing on the alienation factor. Int J Hum Ecol 2002;3:1-19

2. Chang MK, Man Law SP. Factor structure for young's internet addiction test: A confirmatory study. Comput Human Behav 2008;24:2597-2619. https://doi. org/10.1016/j.chb.2008.03.001

3. Chen K, Chen I, Paul H. Explaining online behavioral differences: An internet dependency perspective. J Comput Inform Syst 2001;41:59-63. https://doi.org/10 $.1080 / 08874417.2001 .11647009$

4. Jang KS, Hwang SY, Choi JY. Internet addiction and psychiatric symptoms among Korean adolescents. J Sch Health 2008;78:165-71 https://doi.org/10.1111/ j.1746-1561.2007.00279.x

5. Canan F, Ataoglu A, Nichols LA, Yildirim T, Ozturk O. Evaluation of psychometric properties of the Internet addiction scale in a sample of turkish high school students. Cyberpsychol Behav 2009;13:317-320. https://doi.org/10.1089/cpb.2009.0160

6. Ko CH, Yen JY, Yen CF, Chen CS, Chen CC. The association between internet addiction and psychiatric disorder: A review of the literature. Eur Psychiatry 2012;27:1-8. https://doi.org/10.1016/j. eurpsy.2010.04.011

7. Borsting E, Chase C, Tosha C, Ridder WH 3rd. Longitudinal study of visual discomfort symptoms in college students. Optom Vis Sci 2008;85:992-998. https://doi.org/10.1097/OPX.0b013e31818883cd

8. Porcar E, Pons AM, Lorente A. Visual and ocular effects from the use of flat-panel displays. Int $\mathrm{J}$ Ophthalmol 2016;9:881-885. https://doi.org/10.18240/ ijo.2016.06.16

9. Kim DJ, Lim CY, Gu N, Park CY. Visual fatigue induced by viewing a tablet computer with a high-resolution display. Korean J Ophthalmol 2017:31:388-393. https:// doi.org/10.3341/kjo.2016.0095

10. Suh YW, Na KH, Ahn SE, Oh J. Effect of ambient light exposure on ocular fatigue during sleep. J Korean Med Sci 2018;17:33:e248. https://doi.org/10.3346/ jkms.2018.33.e248

11. Günüç $S$, Kayri M. The profile of internet dependency in Turkey and development of internet addiction scale: Study Of Validity\&Reliability. H.U. Journal of Education 2010;39:220-232.
12. Wu XS, Zhang ZH, Zhao F, et al. Prevalence of internet addiction and its association with social support and other related factors among adolescents in China. J Adolesc 2016;52:103-111. https://doi.org/10.1016/j. adolescence.2016.07.012

13. Sağlan R, Atay E, Demirtaş Z, Öcal EE, Arslantaş D, Ünsal A. Evaluation of internet addiction and dry eye disease among secondary and high school students. Euras J Fam Med 2017;6:117-126.

14. Davey S, Davey A. Assessment of smartphone addiction in Indian adolescents: A mixed method study by systematic-review and meta-analysis approach. Int J Prev Med 2014;5:1500-1511.

15. Nakamura S, Kinoshita S, Yokoi N, et al. Lacrimal hypofunction as a new mechanism of dry eye in visual display terminal users. PLoS One 2010;5:e11119. https://doi.org/10.1371/journal.pone.0011119

16. Park M, Ahn YJ, Kim SJ, You J, Park KE, Kim SR. Changes in accommodative function of young adults in their twenties following smartphone use. J Korean Ophthalmic Opt Soc 2014;19:253-260. https://doi. org/10.14479/jkoos.2014.19.2.253

17. Park KJ, Lee WJ, Lee NG, Lee JY, Son JS, Yu DS. Changes in near lateral phoria and near point of convergence after viewing smartphones. J Korean Ophthalmic Opt Soc 2012;17:171-176.

18. Portello JK, Rosenfield M, Bababekova Y, Estrada JM, Leon A. Computer-related visual symptoms in Office workers. Ophthalmic Physiol Opt 2012;32:375382. https://doi.org/10.1111/j.1475-1313.2012.00925.x

Pamukkale Üniversitesi Girişimsel Olmayan Etik Kurulu'ndan 25.12.2018 tarih ve 24 sayılı toplantı karar ile izin alınmıştır. 